\title{
Multilingual and Multicultural Managers' Effects on Team Performance: Insights from Professional Football Teams
}

\author{
Mike Szymanski, \\ EGADE Business School, Mexico \\ Ilan Alon, \\ Universitetet i Agder, Kristiansand, Norway, and \\ Komal Kalra \\ University of Victoria, Canada
}

\begin{abstract}
Purpose: In this study, micro-foundations of strategy as the theoretical framework to study the effect of managers' individual characteristics on multinational team performance are adopted. In particular, the purpose of this paper is to study managers' multilingual communication abilities and multicultural background, and their role in, respectively, effectively reconfiguring team human assets and sensing cognitively distant opportunities and threats.

Design/Methodology/Approach: This study uses national football teams competing in national and international competitions and their coaches' characteristics as the data set to test the theory. Using random coefficient modeling and ordinary least square regression, this paper analyzes two samples of 222 and 79 teams and found that both these characteristics contribute to team performance; however, their effects differ depending on the team environment.

Findings: Multicultural managers contribute positively to team performance only when the team is operating in a highly diverse environment, their effect is not statistically significant in homogeneous environments. In less diverse environments, it is the multilingual manager who can improve team performance through more efficient communication and greater effects of leadership on the team.
\end{abstract}


Originality/Value: Managers' characteristics such as their multicultural background and multilingual capabilities affect team performance. In particular, these effects come into play in highly diverse and international settings. Micro-foundation literature is advised to focus on the internationalization and multicultural backgrounds of managers as a precursor for organizational international performance.

Keywords: Global leadership, Microfoundations, Cross-cultural management, Organizational performance, Multiculturalism, Multilingualism, Global teams, Microfoundations of strategy, Multinational teams

Paper type: Research paper

\section{INTRODUCTION}

The most successful organizations typically use dynamic capabilities to seize opportunities ahead of competitors (Eisenhardt and Martin 2000, Helfat and Peteraf 2015, Teece et al., 1997). Much theorizing about how dynamic capabilities drive performance focuses on organizational factors such as internationalization capabilities (Cuervo-Cazurra, 2012; Felin et al., 2015). However, organization-level explanations ignore that strategic decisions about knowledge management, resource allocation, and strategic posture are made by individual managers at the top of the organization (Finkelstein and Hambrick, 1996). That is, individuals and their interactions underpin firm-level abilities and outcomes through managerial capabilities that are valuable, rare, and imperfectly imitable, thus becoming "microfoundations" of strategy (Barney and Felin, 2013; Felin et al., 2012; Foss and Pedersen, 2014; Helfat and Peteraf, 2015). The literature of international business (IB) also appreciates the role of personal characteristics in business performance. Recent examples from the literature show that microfoundations are instrumental 
in organizational success on the international stage. For instance, Mostafiz et al. (2019) found the personal antecedents relevant to identifying international opportunity and successful internationalization. Vora and Kostova (2019) proposed that peoples' psychological attachments (individual-level phenomenon) partially drive headquarters-subsidiary relationships (organizational-level phenomenon). We subscribe to the stance that analyzing managers' and executives' individual characteristics may shed light on why some organizations outperform the rest on the international stage. As business organizations of today are becoming culturally and linguistically more diverse, understanding the role of individual managers and executives leading such multilingual and multicultural teams becomes of paramount importance. When individuals responsible for strategic direction are embedded in such complex settings, efficient communication across linguistic and cultural fault lines is a factor for success in multinational operations. Multinational companies has recognized that multiculturals, i.e. individuals who know, identify with, and internalize more than one culture (Vora et al., 2019), are valuable assets for organizations operating across national and cultural borders (Fitzsimmons, Miska, and Stahl, 2011; Fitzsimmons, 2013; Furusawa and Brewster, 2015). Similarly, the international business literature provides examples of managers' linguistic (multilingual) abilities contributing to multinational team performance (Tenzer and Pudelko, 2015, 2017; Zander et al., 2011). While culture and language are closely related constructs as "language is the vehicle for culture; cultural values are reflected in the language spoken" (Selmier and Oh, 2013: 487), they are not identical. Yet, the differences between the effects of multiculturalism and multilingualism are rarely studied. For example, people with multicultural backgrounds serve team performance by bridging cultures and facilitating intra-team negotiation (Kiesel and Haghirian, 2012; Friedman and Liu, 2009), it is unclear whether this is an effect of their multiculturalism (knowledge and 
experience of cultures) or multilingualism (commanding more than one language). Matveev and Nelson (2004) established that cross-cultural understanding is essential for effective functioning of teams in global organizations, but language provides the communicative frame to activate the expression and understanding of complex social issues (Welch and Welch, 2008). Both skill sets - multiculturalism and multilingualism—contribute to team and organizational performance, but the boundary conditions for their effects are unclear as speaking a language fluently is rarely separated from culture and the results may be similar (Selmier and Oh, 2012). Furthermore, there might be overlap between both skill sets because people often become at least partially multicultural while acquiring languages and vice versa.

The aim of this article is to analyze whether managers' multilingual and multicultural backgrounds have an impact on the performance of professional football teams. While there are significant differences between professional sport teams and more traditional organizations, the challenges faced by managers in multinational corporations (MNCs) and elite team coaches are similar: managing highly skilled professionals of various national and cultural backgrounds; dealing with diverse internal and external stakeholders, adapting strategy to changing environmental conditions, and so on (Krause and Szymanski, 2019). To test our hypotheses about those effects, we collected biographical information about managers who lead 482 football teams in environments of diverse levels of international competition and cultural diversity. We offer valuable insights for sport teams owners and executives on the desired characteristics of coaches leading multinational teams. Further, we seek to contribute to the general literature on managing multicultural and multilingual teams, especially in industries characterized by high demand for effective team communication. 
Our study makes two modest, yet important contributions to the literature. First, it tests the boundary conditions of how multicultural managers affect team performance, extending previous works by Fitzsimmons et al. (2011), Dau (2016), and Szymanski et al. (2019). We found that multicultural managers do not enhance the performance of multicultural teams in homogeneous external environments, but their multicultural background becomes instrumental

for success in more diverse international settings. Second, multilingual managers of international teams competing in less diverse environments can improve performance through more efficient communication and leadership. Our dataset of football teams reveals the differential effects of multilingualism and multiculturalism, clarifying what Doz and Kosonen (2010) call "metacapabilities" needed to succeed in global and highly diverse business climates.

In what follows, we review the literature on microfoundations of strategy, focusing on multilingual and multicultural managers, and summarize current research concerning multiculturals and language in international business. Then we develop two hypotheses about the effects of multilingualism and multiculturalism and explain data collected to test them. The results section is followed by a discussion of the theoretical and practical implications of our findings.

\section{LITERATURE REVIEW}

\section{Microfoundations of Strategy and Performance in International Business}

Research into the microfoundations of strategy tries "to unpack collective concepts to understand how individual-level factors impact organizations" (Felin et al., 2015: 576) and how personal actions and interactions mediate macro constructs (Abell et al., 2008). Teece (2007) proposed a framework for the microfoundational analysis of dynamic capabilities, and Helfat and Peteraf (2015) elaborated upon their cognitive foundations. While the original view of dynamic 
capabilities saw them as "being resident in the firm's organizational processes" (Teece et al., 1997: 524), the more recent trend is to see them as residing "with individual managers and the top management team" (Teece, 2014: 332). Top managers drive firms' performance by sensing opportunities and threats, seizing opportunities, and reconfiguring resources in shifting competitive environments. They sense opportunities and threats through superior perceptions and attention, seize opportunities through superior problem-solving abilities, and better configure resources through social cognition and language skills (Helfat and Peteraf, 2015: 837). Such qualities are erratically distributed among managers, and whoever possesses them can inspire performance, particularly if they can embed such qualities within organizations (Gavetti, 2012; Helfat and Peteraf, 2015).

Dynamic capabilities based on organizational processes may collapse in dynamic, highvelocity and high-flux markets (Eisenhardt and Martin, 2000), but those based on people might be the source of sustainable competitive advantage in such environments. It must be stressed that it is not the individuals per se that lead to superior performance, but rather a particular mix of skilled personnel, processes and routines, and administrative coordination (Teece, 2014). Nevertheless, it is the manager who uses cognition to select and encode experiences into routines, bundle routines into capabilities, and match capabilities and environment (Eggers and Kaplan, 2013). Further, the match between the individual and the environment plays a crucial role in the development of firm level dynamic capabilities as "the exposition to the same macrolevel stimuli does not necessarily result in the same (...) reactions in various individuals," hence 'the dynamic capabilities framework requires considerations of individuals' conditions for action and individuals' level of influence in the organization" (Kurtmollaiev, 2020: 8). 
International business research has always appreciated the role of individual managers in internationalization of companies and coordination of international business activities, yet for long time did not adopt the microfoundational perspective (Foss and Pedersen, 2019). However, recently international business/international management (IB/IM) scholars have adopted such approach and studied more individual-centered phenomena such as managerial knowledge and experience or the composition of top management teams of internationalizing firms, international HRM or international entrepreneurship. One of the great challenges is to link MNEs' outcomes to the individuals and their interactions as "ultimately, it is individuals and not the subsidiaries that are the agents (Foss and Pedersen, 2019: 1617). It is not firms that are different from each other in terms of "psychic distance" or "cultural distance," but the individual employees and managers. Therefore, more scholarly attention shall be paid to the individuals and their role in organizational phenomena taking place in MNEs.

\section{Multicultural Managers and Microfoundations}

The literature recognizes multicultural managers - those who know, identifiy with, and internalize more than one culture (Vora et al., 2019)—as strategic assets for multinational companies (Furusawa and Brewster, 2015; Fitzsimmons, Miska, and Stahl, 2011). Thanks to their cultural metacognitive strategies and cross-cultural communication and negotiations skills and experience, they are poised for success as leaders of international teams (Brannen and Thomas, 2010). From the microfoundational perspective, multicultural managers potentially are more likely to sense, seize, and reconfigure cognitively distant opportunities across countries and cultures. Multicultural managers are accustomed to perceiving matters globally. They are capable of more cognitively complex cultural constructions than monoculturals, demonstrate better understanding of cultural differences, and better adapt to cross-cultural situations (Benet- 
Martínez and Haritatos, 2005; Tadmor et al., 2009). Their experience switching cultural frames allows them to expose avenues for organizational growth.

When it comes to seizing opportunities, multicultural managers bring multiple perspectives and greater creativity to problems (Leung et al., 2008), cultural knowledge (BenetMartínez and Haritatos, 2005), and flexibility (Chiu and Hong, 2004, 2005). These cognitive attributes may help them enact global strategic plans. Finally, multicultural managers' expertise in cross-cultural communication and conflict mediation may help them reconfigure resources by persuading culturally diverse stakeholders to accept and endorse change (Fitzsimmons et al., 2011; Kiesel and Haghirian, 2012). These cognitive attributes may drive flexibility of international organizations, a competitive advantage in global environments.

\section{Multilingual Managers and Microfoundations}

Studies pay abundant attention to the benefits of multiculturalism within multinational corporations (MNCs), but language skills are needed to benefit from them. For that reason, more studies now focus on language and language systems in leading MNCs (Barner-Rasmussen and Aarnio, 2011; Conger, 1991; Harzing et al., 2011; Tenzer and Pudelko, 2015, 2017; Zander et al., 2011). Leaders' linguistic skills might affect results (Tenzer and Pudelko, 2017), and overcoming language barriers is important (Harzing et al., 2011; Tenzer and Pudelko, 2015). Studies have considered leadership itself as a specific language or behavior akin to language (Conger, 1991; Marturano et al., 2010; Pondy et al., 1989). Pondy et al. (1989) view leadership as "a language game." Hence leaders must be rhetorically effective to influence followers' behaviors (Fairhurst, 2005; Fairhust and Sarr, 1996).

That might be relatively easy when managers and leaders speak the same language, but complexity emerges among multilingual teams. Efficient communication is critical in highly 
interdependent teams, where the team success depends on close cooperation of team members. Mutual learning and knowledge sharing cannot be accomplished by using interpreters to constantly bridge between languages (Selmier and Oh, 2013). Having a good command of common language (often the team host country language or a corporate lingua franca) enables to better express motivation and plans and embed them into a context familiar to the other teammate. Studies have analyzed how multilingual teams set an official language for communication (Steyaert et al., 2011) across levels within MNCs (Barner-Rasmussen and Aarnio, 2011). Doing so is important because language differences affect power dynamics of multinational teams by limiting the effectiveness of hierarchical position or expertise in validating a leader (Tenzer and Pudelko, 2017). Further, any successful engagement in multinational interactions containing high relational component, requires an understanding of nuance and tacit meaning (Brannen, 2004). MNEs (and managers) who chose to use translators in their day-to-day business encounters lose the ability to understand spoken and unspoken signals in business communication (Selmier and Oh, 2013).

The relation between leader-team communication in cross-cultural and cross-lingual context is not well understood, especially given its relative importance in international organizations (Zander, 2005). Nevertheless, efficient communication across linguistic fault lines is a factor for success in multinational operations, and managers' multilingualism becomes a microfoundation of the "metacapability" of global organizations (Doz and Kosonen, 2010). Language awareness and competence are needed for MNCs "to perceive complex changes in multiple local and global environments (...), dialogue with the stakeholders in those communities to inform better decisions, and reconfigure internal resources and implement new plans" (Brannen and Mughan, 2018: 55). In this study, we follow this research avenue and 
examine the relationship between managers' multicultural identity, multilinguistic skills and team performance.

\section{HYPOTHESES DEVELOPMENT}

Drawing from microfoundations of strategy, we theorize about how managers' multilingualism and multiculturalism effects differ in various competitive environments. We build our hypotheses on the assumption that more globalized competitive environments require different skills and capabilities than local environments (Ghemawat, 2005; Reiche, Bird, Mendenhall, and Osland, 2017). International business literature has already adopted the configurational fit perspective when analyzing microfoundations of performance and recognized international managers' effect on teams and organizations (e.g., Hutzschenreuter and Horstkotte, 2013; Szymanski, Fitzsimmons, and Danis, 2019). We follow suit and theorize about the effect of two particular characteristics, multilingualism and multiculturalism, in two archetypical types of competitive environments: culturally homogeneous (local) and culturally heterogeneous (global).

\section{Culturally Homogeneous and Highly Heterogeneous Environments}

Environmental complexity is one of antecedents of team performance (McGrath, 1964). Because "individuals are nested in teams, which in turn are nested in organizations, which exist in environments" (Mathieu et al., 2008: 412), team members may understand the role of the environment differently, thus affecting team performance. The team/organizational environment may differ on many dimensions, but in this study we focus on the degree of globalization and diversity in competitive environments, which in turn determine effective strategies and leadership. By the degree of globalization we refer to the geographical and cultural aspects, and not to the level of competition. Some industries, such as shipbuilding, automobiles, or industrial 
machinery are highly global, hence companies from multiple countries often compete with each other for public and corporate customers based all over the world (Makhija et al., 1997; Bartlett and Ghoshal, 2002). Conversely, there are industries in which competition is by and large local and independent within each country (Harzing, 2000). Each environment requires a different toolkit for managers to succeed. Global competitive environments are characterized by high variety of regulatory contexts, multiple and diverse stakeholders, and a complex web of languages and cultures (Roth and Kostova, 2003). Further, global environments exhibit higher levels of flux (i.e., the frequency, velocity and unpredictability of environmental changes), which refers to the frequency, velocity and unpredictability of change (Reiche et al., 2017). As a result, such environments demand faster reactions and adaptation to competitors' strategies and tactics that are unheard-of in the organization's home market. When market players come from a variety of backgrounds, they bring to the market their idiosyncratic approaches to competition, which require managers to develop high sensing skills and be ready to react quickly to unexpected and rapid changes (Eisenhardt et al., 2010). International business literature shows that managers of multicultural background (Szymanski et al., 2019) or with significant international experience (Peeters et al., 2019) might excel in such environments.

Conversely, less global (local) environments are highly competitive as well, however, they pose different challenges and, thus, demand a different managerial toolkit. While the variety and flux might be lower in less global environments, the playing field is equally familiar to all competitors who understand all idiosyncrasies of their home market. In such environments, competitive advantage stems from highly efficient incremental change, which depends on managers perceiving, seizing and reconfiguring cognitively proximate opportunities. In such environments, multicultural managers might not get a chance to take advantage of their skills. On 
the other hand, multilingual managers might be more effective at communicating their strategy to team members, and thus improving team performance. We adopt this configurational fit perspective and examine the effect of managers' multiculturalism and multilingualism on team performance in both types of environments.

\section{Multicultural and Multilingual Managers}

With the increasing globalization of firms, management of cultural and linguistic diversity have become the new organizational reality (Kulkarni, 2015). Traditionally, international business (IB) scholars have associated multinational teams (i.e., teams with team members coming from various national backgrounds) with either cultural or linguistic diversity, assuming that multinational teams are by default multicultural and multilingual. Although such assumption is often correct, there are teams that are monolingual and multicultural (for example, a team with members coming from England, Ireland, and the US), and there are teams that are monocultural yet multilingual (e.g., local teams in multilingual countries like India). Similarly, managers can be multicultural and multilingual, but can also be multicultural and monolingual and vice versa. The effects of multiculturalism and multilingualism can be quite different.

Early studies proposed that multicultural individuals can boost performance of multinational organizations and global businesses (Brannen et al., 2009; Hong, 2010; Fitzsimmons et al., 2011). Because MNCs operate across national borders (Brannen and Thomas, 2010), employees with cross-cultural skills could be important resources. Within MNCs, however, not all teams operate internationally or have members from several countries. For example, a local sales team might operate in a familiar environment and be versed in the local culture (e.g., local nationals). In such situations, task performance is driven by team members' experience and whether their skills fit the market. In such cases, multicultural 
managers and/or team members likely have limited effect because the environment may not require cross-cultural skills. Empirical research has confirmed that teams led by managers with multicultural backgrounds outperform teams led by monocultural managers only when the team is embedded in a highly heterogeneous environment (Szymanski et al., 2019). Conversely, Szymanski et al. (2019) found that multicultural managers are less efficient in local (homogeneous) environments, at times performing worse than local monocultural managers. Their cognitive toolkit enables them to perform well in multicultural environments, but it does entail universal advantage over monoculturals, who may better recognize and pursue cognitively proximal opportunities.

We look beyond multiculturalism to focus on multilingualism of managers. "Language lies at the heart of international business activities" (Brannen et al., 2014, p.495), therefore, effective and efficient communication is critical for the success of multinational teams and organizations as employees within MNCs are frequently confronted with participating in conversations and tasks involving linguistically diverse colleagues (Kulkarni, 2015). Processing of knowledge and information becomes even more challenging when not all team members possess a high level of proficiency in the official corporate language, or the de facto language of the team. As a result, certain individuals might feel incompetent or frustrated (Piekkari et al., 2005). Multilingual individuals who are proficient in the corporate language as well as other prominent languages of the specific within-team linguistic subgroups could bridge the communication gap in their teams (Barner-Rasmussen, Ehrnrooth, Koveshnikov, and Mäkelä, 2014). However, multilingualism is neglected as a leadership advantage because it often is presumed that English is the lingua franca of business. However, leadership is socially construct in which language is important (Fairhurst, 2005; Fairhust and Sarr, 1996). Dau (2016) argues 
that multicultural managers contribute most to team performance when their characteristics align with their teams'. We echo this argument and assert that multilingual managers can establish better communication with their teams, especially when their members speak native languages. We discard the assumption that English is the communication platform for an entire team and hypothesize that multilingualism allows dyadic connections among team members. Managers who lack multilingual ability to influence international teammates in their language will not reconfigure personnel effectively. Therefore, ceteris paribus, multilingual managers extract the potential of multinational teams, leading to superior performance.

In the sport context that we adopted for this study, both multilingualism and multiculturalism play an important role, yet the effects are contingent on the environment of the team. Similarly to MNEs' managers, football managers face challenges such as adaptation to the external environment (including the local institutions and competitors) and managing a diverse, highly-skilled workforce (Krause and Szymanski, 2019). When placed in a relatively culturally homogeneous local competitive environment, competitive advantage comes from high efficiency and consistency (Reiche et al., 2017). Multilingual managers are the source of competitive advantage for the team as they are able to more clearly explain game plans, communicate more efficiently in practices, and ease the adaptation process for the foreign members of the team. We propose:

Hypothesis 1: In homogeneous competitive environments professional football teams led by multilingual managers will outperform teams led by monolingual managers. 
However, multilingual managers may lose competitive advantage when teams move to diverse environments. It is not to say that multilingualism does not contribute to efficient team communication, but rather that other factors comes to the front and become the source of competitive advantage. The characteristics of the competitive environments determine the required patterns of dynamic capabilities (Eisenhardt and Martin, 2000). Managers operating in global competitive environments need to address higher levels of flux (i.e., the frequency, velocity and unpredictability of environmental changes), which requires them to be observant and highly flexible (Reiche et al., 2017). When competitive environments become more culturally diverse, leaders face opportunities that "lie outside the purview of predominant ways of thinking" (Gavetti, 2012, p.268). Global, highly heterogeneous environments change faster due to more variance in competition, both in terms of other market players and regulations (Roth and Kostova, 2003; Eisenhardt et al., 2010). Organizations competing on a global stage need to adapt quickly to various local institutions (including national and regional cultures) and to address strategies of their competitors which come from all over the world. Such idiosyncratic challenges demand managers of particular skillsets. Lucke et al. (2014) found that leaders with multicultural backgrounds can reference more than one set of cultural norms to interpret the competitive environment. Szymanski et al. (2019) found that managers with multicultural backgrounds outperform monocultural peers in culturally diverse environments. In such environments competitive advantage shifts from team efficiency achieved by communication ability of multilingual managers to the multicultural leader's sensing ability (i.e., to recognize cognitively distant threats and opportunities).

In the context of international professional football, higher levels of cognitive complexity enable multicultural managers to quickly adapt to opponents' unfamiliar strategies and tactics by 
recognizing more foreign, cognitively distant patterns of play. Multicultural managers may quickly reshuffle their teams tactics and rosters to effectively address competitors coming from various backgrounds. In a highly global, culturally diverse environment, the competitive advantage comes from ability to react quickly to high levels of flux and variety. Therefore, we propose:

Hypothesis 2: Professional football teams led by multicultural managers will outperform teams led by monocultural managers in heterogeneous competitive environments.

\section{METHOD}

We collected data for 291 men's professional football (soccer) teams participating in 17 national competitions (i.e., national leagues) and 191 teams participating in six regional competitions during 2012-2013 to draw a parallel between teams participating in national leagues and international/regional competitions and companies competing locally and globally. We chose professional and international association football (soccer) as our research context because of methodological advantages such as abundance of high quality data (Wolfe et al., 2005) and comparability of results across the globe (Szymanski et al., 2020). Krause and Szymanski (2019) argued that soccer resembles other global industries (e.g., manufacturing) because (1) it is a global activity, (2) the service is standardized and internationally comparable, (3) performance is accurately measured and data are comparable, (4) the industry is competitive and subtle differences may be important, and (5) "the global nature of soccer facilitates the transfer of (knowledge,) technology, and skills (Krause and Szymanski, 2019: 2981). Football has been the context for studies of manager migration and international experience (Peeters et al., 2019), global careers (van Bakel and Salzbrenner, 2019), and the effects of managers' multiculturalism on team performance (Szymanski et al., 2019). 


\section{Sample}

We built two datasets to emulate homogeneous and diverse competitive environments. The first dataset included information about all teams, players, and coaches participating in 17 national football leagues (i.e., competitions where teams from only one country are allowed to compete): England (20); Spain (20), Italy (20), France (20), Germany (18), Portugal (18), the Netherlands (18); Turkey (18); Ukraine (16), Poland (16), Czech Republic (16), Belgium (16), Switzerland (10); Brazil (20); Argentina (20); China (16), South Korea (14), for a total of 294 teams. Because of discrepancies in collected performance and team data, we dropped three teams for a final sample of 291 teams.

To examine highly diverse environments, we built another dataset of teams participating in international professional football competitions (i.e., competitions where teams from multiple countries compete, usually with no more than four teams from the same country): UEFA Champions Leagues (32 teams) and Europa League (48); South American Copa Libertadores (32) and Copa Sudamericana (16); Asian AFC Champions League (32) and AFC Cup (32); and African AFC Champions Leagues (32), for a total of 224 teams. However, due to the lack of data on some teams and discrepancies in managers' info, only 191 teams (82\%) are included in the final sample.

All data was collected from the International Federation of Football History and Statistics, Whoscored, and Transfermarkt services. Biographical information about all 482 managers was retrieved from their teams' websites and media reports and cross-referenced with the Transfermarkt database. 


\section{Variables}

Table 1 presents arithmetic means, standard deviations, minimum and maximum values, and correlations for all variables used to test Hypothesis 1.

Table 1

Variables used to test Hypothesis 2 appear in Table 2.

Table 2

\section{Dependent Variables}

Team Performance was measured as a wins per game ratio (that is the percentage of games won out of all games played by the team in a given competition. It is a common measure in management studies that use sports as a research context (e.g., Smart and Wolfe, 2003; Szymanski et al., 2019).

\section{Independent Variables}

Multiculturalism is a dummy variable, indicating individuals with multicultural backgrounds. Vora et al. (2019) describe multiculturals as people who know, identify with, and internalize more than one culture. We followed the recent studies on managers' effect on team performance using football data (Peeters et al., 2019; Szymanski et al., 2019) and retrieved biographical information of all coaches from Transfermarkt, Whoscored, and official team websites to create a qualitative dataset. Two graduate assistants coded data for whether a coach (1) was born to immigrant parents, (2) was born to parents from different countries, (3) moved to 
a new country as a child, (4) moved to a new country as a teenager, or (5) moved to a new country as an adult and identifies with it (e.g., lived for more than five years, has dual citizenship, or a host-country wife).

Multilingualism is a continuous variable indicating the number of languages in which the manager can communicate. We based the count on Tranfermarkt and Whoscored data and on coach's official profiles and media reports. We eliminated all cases in which a manager's language skills were described as "weak," "poor," or "rudimentary."

\section{Control Variables}

We controlled for team-level variables that are proxies for a team's human capital potential and can potentially influence team performance. Team Average Salary (measured in thousands of British pounds) is an accepted proxy for players' past and potential performance (Lucifora and Simmons, 2003; Smart and Wolfe, 2003). Team Average Age (measured in years) is a proxy for a team's physical abilities (Maderer et al., 2014). Number of Nationalities measures a team's diversity by counting the number of players' countries of origin. Although an imperfect proxy, it suggests the number of native languages spoken by teammates. We groupcentered average salaries and number of nationalities to reflect levels of financial potential and internationalization of leagues.

We controlled for manager-level variables that are proxies for coaching experience, following recently published work (Peeters et al., 2019). Manager's Age is a continuous variable to measure a manager's experience. Foreign manager is a dummy variable indicating whether the coach is a foreign national. Tenure of manager (in years) indicates how long and deeply managers are nested within teams and organizations. Hambrick and Fukutomi (1991) suggested that new top executives begin with a technical knowledge deficit (about the organization), but 
steadily learn their organizations and environments, hence managers' tenure plays an important role.

\section{RESULTS}

To test Hypothesis 1 we ordinary least square (OLS) model analysis on the sample of 291 teams in 17 homogeneous (local) environments. We built five models of increasing comprehensiveness (Table 3).

Table 3

This base model includes only team-level variables to examine how extensively the quality of human capital determines team performance. The model revealed that player talent (proxied by salaries) indeed enhances team performance, but average age has a negative effect. Model 1 incorporates control variables for managers such as age, tenure, and a dummy for foreign managers. Tenure and foreign managers have a positive significant effect on team performance. The next two models include all previous variables and two focal independent variables - multilingualism and multiculturalism (separately). The effect of multilingualism is positive and statistically significant. The positive effect of multiculturalism is not statistically significant at $p<0.1$. The full model includes all variables and the results show that the effect of multilingualism remains positive and statistically significant. In all models we controlled for the league in which the team participated to account for potential differences. Adjusted $R^{2}$ estimates show that the model fit increased with each set of variables. 
To test Hypothesis 2 we conducted ordinary least squares (OLS) regression on 191 teams, controlling for the competition in which they participate (6). Following the logic of the first set of regressions, we tested five models of increasing comprehensiveness (Table 4).

\section{Table 4}

The baseline model again controlled for team-level variables and the second for managerlevel controls. The next two models included all controls and multilingualism and multiculturalism, separately. The full model included all control variables plus the coach's multilingualism and multiculturalism. The latter had a positive statistically significant effect and the former a negative yet statistically insignificant (at $p<0.1$ ) effect on team performance. Differences in adjusted $R^{2}$ show the explanatory power increased with each model.

We performed a battery of robustness tests to check reliability of our findings. First, we applied another estimation technique to assure results are not sensitive to the selected method. We re-tested Hypothesis 1 using random coefficient modelling technique. The likelihood ratio test, comparing the random coefficient model against ordinary least square regression model, revealed that the former did not perform better than the latter, hence OLS should be used as the preferred method. Noteworthy, no changes appeared in significance levels of predictor variables. Second, we added control variables for the coach (coaching achievements, experience as a player) and team (number of international-level players, number of professional games played) but the new models showed lower explanatory power than the original models, indicating the added variables confounded the results. The direction and significance of predictors remain unchanged. 


\section{DISCUSSION}

The aim of this article was to examine the differences in effects of managers' multilingualism and multiculturalism. We grounded our hypotheses in the microfoundational theory that managers drive firms' dynamic capabilities by sensing (perceiving opportunities), seizing (making good decisions based on opportunities), and reconfiguring (transmuting those opportunities) (Helfat and Peteraf, 2015). To study these effects, we collected detailed data on 482 association football teams participating in 23 different competitions. In contrast to many other studies on multicultural and multilingual managers, we analyzed real-life teams working together over a long period of time and competing in two types of highly demanding environments.

Our findings reveal that both coaches' multiculturalism and multilingualism have a positive effect on team performance, yet the effects are contingent on the environment of the team. In a sense, our findings echo previous results showing that multicultural managers generally better identify opportunities and drive team performance in highly diverse settings (e.g., Szymanski et al., 2019), which is consistent with broader IB literature highlighting the positive relation between managerial cognition and identification of international opportunities by exporter-manufacturers (Mostafiz et al., 2019). Ramsey et al. (2016) proposed that individual abilities such as cultural intelligence and global mindset (both common among multiculturals) aid in understanding an organization's strategic outcomes, such as managerial effectiveness, human resource management, and organizational performance. Multicultural knowledge and metacognitive ability to process cultural information poise multicultural managers for success in international settings (Fitzsimmons et al., 2011; Vora et al., 2019). Indeed, our results demonstrate that multicultural football coaches possess an advantage over their monocultural 
peers when leading teams in international competitions. However, we caution against premature generalization that all MNEs' multicultural managers benefit the same level of advantage. While the football industry sufficiently resembles other knowledge- and cooperation-intensive industries (Krause and Szymanski, 2019; Szymanski et al., 2020), there significant differences which must be addressed. Participating in a domestic league can be quite easily translated to competing on a domestic market, but playing in an international competition is not exactly alike entering a new foreign market. Unlike MNEs, football teams do not face the differences in legal, political, economic, and sociocultural environments when playing a single game overseas. This means that football teams may not perceive liabilities of foreignness because they are not facing heterogenous environments, hence they do not need to be embedded in environments of the host country. On the other hand, competing internationally means playing against teams coming from (at least) three different countries, forcing the coaches to quickly analyze, recognize, and successfully address various playing patterns and styles of foreign teams. Because national playing styles are heavily influenced by national cultures (Bangsbo, Reilly, and Hughes, 1997; Bangsbo and Peitersen, 2000), multicultural coaches are faster and more effective at recognizing such patterns and addressing them with their own teams' tactics. These results further suggest the importance of context in considering microfoundations in international business. Our findings demonstrate that the cognitive and behavioral attributes of multicultural managers are more likely to provide foundations for flexible, discontinuous, dynamic capabilities, providing competitive advantage but only within highly diverse global environments.

Another contribution is the evidence of positive effect of managers' multilingualism. Language proficiency has been long recognized as arguably the most foundational communication skill in multinational teams; without ability to speak a language, skills like 
nuance, tact, and other communication techniques are frequently out of reach. While speaking one of the most common languages (such as English or French) is often sufficient in short term business interactions (Selmier and Oh, 2012; 2013), it is the ability to speak the local language that helps foreign managers establish meaningful relations and build long term collaboration (Selmier et al., 2015). Our results show that managers who only speak a local language (or just the corporate lingua franca) may be outperformed by managers able to speak multiple languages, especially when their teams are multinational. The particular dataset we collected did not allow us to investigate deeper into the actual mechanisms of this effect, but we suspect it is a combination of closer relationships with individual team member, more effective leadership, and ability to build initial connections and attracting foreign talent. Interestingly, our analysis revealed a puzzling result when it comes to the effects of multilingualism in various environments. We found that multilingualism has a non-significant effect in international competitions, even though teams (their compositions) are, by and large, the same as teams in domestic competitions. The absence of evidence is not an evidence of absence of an effect, nevertheless it is a puzzling result. While consistent with our initial assumption that each type of competitive environment requires a different skillset, with the culturally diverse environment requiring more multicultural background; we did not expect that multilingualism would lose its importance as communication between the manager and players on the field is equally important in a domestic and an international game. Similarly, pre-game preparations still happen in the same, multinational group of players and staff. Therefore, the effect of multilingualism should be equally strong in both teams of environments. One possible explanation is the fact that it is the best teams from domestic competitions that participate on the international stage. Multilingual managers might enhance team communication to such level that the team dominates other local 
teams led by monolingual managers. Then, in international competitions there are more teams led by multilingual managers (i.e., multilingualism is more frequent/less scarce), thus other characteristics might give the team an edge on the opponent. When compare both samples used in our study (domestic competitions and international competitions), there are some differences in coaches' characteristics. Indeed, all characteristics expected to improve team performance (managers' age, tenure, foreign origins, numbers of languages spoken and multicultural background) are on average higher in for the teams participating in international competitions than for those in domestic ones. This comes as no surprise since it is the best teams that compete internationally, hence either already have outstanding managers or can afford to sign the best ones. Further examining of the regression results in both samples show that some characteristics having significant effect in the domestic competitions (such as managers' tenure or foreign origins) lose their statistical significance in the international competition sample.

Finally, we contribute to the international business literature by studying IB/IM phenomena in less traditional settings. Although sport teams are not directly comparable to more conventional organizations, the challenges faced by their managers resemble those faced by CEOs and managers of large multinational corporations, such as competing on a global stage, dealing with diverse internal and external stakeholders, managing highly skilled professionals, and adapting organizational strategy to dynamic environmental conditions (Peeters et al., 2019; Szymanski et al., 2020; Wolfe et al., 2005). More broadly, we believe there is significant value in studying less conventional contexts as they provide the opportunity to challenge existing literature and provide fresh insights. Several scholars have called for more research in unconventional contexts as a way to spur theory development (e.g., Mol, Stadler, and Ariño, 2017; Hällgren et al., 2018), because substantial and influential contributions to theory have 
often been derived from studies of unconventional contexts, including homelessness and the Port Authority of New York and New Jersey (Dutton and Dukerich, 1991) and organizational restructuring in hospital radiology departments (Barley, 1986), as well as more extreme contexts, such as the Mann Gulch fire (Weick, 1993), the 1996 Mount Everest expedition (Elmes and Frame, 2008), or collective action on United Airlines Flight 93 (Quinn and Worline, 2008), among many others. While one could argue that such contexts are not strictly comparable to the conventional contexts that typify most organization scholarship, insights about management and other business-related topics can and do come from all types of organizations (Bamberger and Pratt, 2010).

\section{Practical Implications}

Organizations within increasingly global environments need managers who excel in culturally diverse, complex, changing markets. Managers with multicultural backgrounds can sense and seize cognitively distant global opportunities in market nuances, and respond more flexibly (Szymanski et al., 2019). Our results confirm that in global settings characterized by cultural diversity, fast-paced change, and intense competition, teams led by multicultural managers outcompete those led by monoculturals.

However, not all companies compete globally, and not all tasks and teams within multinational organizations are multicultural in nature. When competition is less global, workforces less multicultural, and environments more stable, multicultural managers may be less effective than monocultural peers. Conversely, multinational organizations take advantage of their global talent by moving experts and managers between countries to solve local problems. In such cases, a team might be diverse, but the problem (and the team's environment) is local. Our results show that teams working on a local task benefit from managers' linguistic skills, which 
facilitate communication and transmission of experience and information. When the task and environment are local, multiculturalism seems less relevant than ability to explain tasks and motivate teams in their native language(s).

Our findings commend a contingency approach to staffing and managing organizations and teams. The broader environment and team composition must be acknowledged when evaluating capabilities of managers and their contribution to team and organizational performance.

\section{Limitations and Further Research Directions}

While our dataset allowed us to study the effects of managers' cultural backgrounds and language skills, its secondary nature limited potential insights into the actual mechanisms through which managers contribute to team performance. We theorize about the cognitive processes in the discussion section, but more research, preferably using primary data, is necessary to tease out the actual causal relations.

Further, as it is the case for most correlation studies, ours is vulnerable to endogeneity which might be caused by unobserved heterogeneity, reverse causality, and self-selection bias and can significantly affect the validity of research findings (Heckman, 1979). Self-selection bias is of particular importance in the football context as the best managers are valuable on the international market, so they are more likely to be signed by international professional teams and move overseas, thus gaining international experience and in turn gaining multicultural backgrounds and language knowledge. In other words, there is a risk that it is best managers who become multicultural; not multicultural managers who become best.

Finally, the sports context offers numerous advantages to study international management phenomena (Szymanski et al., 2020; Wolfe et al., 2005) but it also differs from the types of 
industries that have traditionally been studied in the mainstream international business and strategy literature, raising some generalizability concerns. The managerial challenges in the world of association football may resemble those of managers in other industries (Peeters et al., 2019; Krause and Szymanski, 2019), but football managers have more interactions with relatively small football teams than their counterparts in other industries who typically manage much larger organizations. In other words, the effects of individual managers in football may be greater than in other industries. Hence, more research is necessary to test how our findings generalize to other contexts.

\section{CONCLUSION}

Language and its effect on team management and leadership remain understudied in international business research (Zander, 2005). We answered the call for more microfoundational research in international business by studying multicultural backgrounds and multilingual communication abilities as important characteristics of managers operating in multinational settings. Further, we studied these effects on team performance in a novel global settinginternational professional football.

Our results indicate that multilingual communication ability helps managers utilize personnel more effectively than using professional interpreters and/or relying on other team members to translate. This finding indicates that a significant part of leadership in multicultural settings (i.e., ability to influence) might be lost in translation. Finally, we found that multicultural leaders can lead teams in a highly heterogeneous competitive environment more effectively than their monocultural counterparts. It is an important observations for management practice: just because leaders are multilingual does not mean they can manage the ambiguities of multicultural environments. A global leader should be, ideally, multilingual and multicultural. 


\section{REFERENCES}

Abell, P., Felin, T., and Foss, N. (2008), "Building micro-foundations for the routines, capabilities, and performance links", Managerial and Decision Economics, Vol. 29 No. 6, pp. 489-502.

Bamberger, P. A., and Pratt, M. G. (2010), “Moving forward by looking back: Reclaiming unconventional research contexts and samples in organizational scholarship", Academy of Management Journal, Vol. 53 No. 4, pp. 665-671.

Bangsbo, J., Reilly, T., and Hughes, M. (Eds.). (1997), Science and Football III: Proceedings of the Third World Congress of Science and Football, Cardiff, Wales, 9-13 April, 1995 (Vol. 3). Taylor \& Francis.

Bangsbo, J., and Peitersen, B. (2000), Soccer Systems and Strategies. Human Kinetics, Champaign, IL.

Barley, S. R. (1986), “Technology as an occasion for structuring: Evidence from observations of CT scanners and the social order of radiology departments", Administrative Science Quarterly, Vol. 18 No. 1 , pp. $78-108$.

Barner-Rasmussen, W., and Aarnio, C. (2011), "Shifting the faultlines of language: A quantitative functional-level exploration of language use in MNC subsidiaries", Journal of World Business, Vol. 46 No. 3, pp. 288-295.

Barner-Rasmussen, W., Ehrnrooth, M., Koveshnikov, A., and Mäkelä, K. (2014), “Cultural and language skills as resources for boundary spanning within the MNC", Journal of International Business Studies, Vol. 45, pp. 886-905.

Barney, J., and Felin, T. (2013), “What are microfoundations?”, The Academy of Management Perspectives, Vol. 27 No. 2, pp. 138-155.

Bartlett, C. A., and Ghoshal, S. (2002), "Building competitive advantage through people", MIT Sloan Management Review, Vol. 43, No. 2, pp. 34-41.

Benet-Martínez, V., and Haritatos, J. (2005), "Bicultural identity integration (BII): Components and psychosocial antecedents", Journal of Personality, Vol. 73 No. 4, pp. 1015-1050. 
Bird, A., and Mendenhall, M. E. (2016), "From cross-cultural management to global leadership:

Evolution and adaptation", Journal of World Business, Vol. 51 No. 1, pp. 115-126.

Brannen, M. Y. (2004), “When Mickey loses face: Recontextualization, semantic fit, and the semiotics of foreignness", Academy of Management Review, Vol. 29 No. 4, pp.593-616.

Brannen, M. Y., and Mughan, T. (2018), "Strategic Agility: The Critical Role of Language”, Pragne, C., and Heracleous, L. (Eds.), Agility. X. How Organizations Thrive in Unpredictable Times. Cambridge University Press. DOI: https://doi.org/10.1017/9781108545884.005

Brannen, M. Y., Piekkari, R., and Tietze, S. (2014), "The multifaceted role of language in international business: Unpacking the forms, functions and features of a critical challenge to MNC theory and performance", Journal of International Business Studies, Vol. 45, pp. 495- 507.

Brannen, M. Y., and Thomas, D. C. (2010), "Bicultural Individuals in Organizations Implications and Opportunity", International Journal of Cross Cultural Management, Vol. 10 No. 1, pp. 5-16.

Brannen, M.Y., Thomas, D.C. and Garcia, D. (2009), Biculturals as Natural Bridges for Intercultural Communication and Collaboration, Proceedings of the International Workshop on Intercultural Collaboration, Stanford University, Palo Alto, CA.

Chiu, C., and Hong, Y. (2004), “The identity of being a Hong Konger: Empirical evidence and implications for Hong Kong's strategic development”, Hong Kong Journal of Social Science, Vol. 26, pp. 43-58.

Conger, J. A. (1991), "Inspiring others: the language of leadership", Academy of Management Perspectives, Vol. 5 No. 1, pp. 31-45.

Cuervo-Cazurra, A. (2012), "Extending theory by analyzing developing country multinational companies: Solving the Goldilocks debate”, Global Strategy Journal, Vol. 2 No. 3, pp. 153-167.

Dau, L. A. (2016), “Biculturalism, team performance, and cultural-faultline bridges”, Journal of International Management, Vol. 22 No. 1, pp. 48-62.

Doz, Y. L., and Kosonen, M. (2010), “Embedding strategic agility: A leadership agenda for accelerating business model renewal", LongRrange Planning, Vol. 43 No. 2-3, pp. 370-382. 
Dutton, J. E., and Dukerich, J. M. (1991), “Keeping an eye on the mirror: Image and identity in organizational adaptation", Academy of Management Journal, Vol. 34 No. 3, pp. 517-554.

Eggers, J. P., and Kaplan, S. (2013), “Cognition and capabilities: A multi-level perspective”, Academy of Management Annals, Vol. 7 No. 1, pp.295-340.

Eisenhardt, K. M., Furr, N. R., and Bingham, C. B. (2010), "Microfoundations of performance: Balancing efficiency and flexibility in dynamic environments", Organization Science, Vol. 21, pp. 12631273.

Eisenhardt, K. M., and Martin, J. A. (2000), “Dynamic capabilities: what are they?”, Strategic Management Journal, Vol. 21 No. 10-11, pp. 1105-1121.

Elmes, M., and Frame, B. (2008), "Into hot air: A critical perspective on Everest”, Human Relations, Vol. 61 No. 2, pp.213-241.

Fairhurst, G. T. (2005), "Reframing the art of framing: Problems and prospects for leadership", Leadership, Vol. 1 No. 2, pp. 165-185.

Fairhurst, G., and Sarr, R. A. (1996), The Art of Framing. Managing the Language of Leadership, Wiley: Jossey-Bass.

Felin, T., and Foss, N. J. (2005), "Strategic organization: A field in search of micro-foundations", Strategic Organization, Vol. 3 No. 4, pp. 441-455.

Felin, T., Foss, N. J., Heimeriks, K. H., and Madsen, T. L. (2012), "Microfoundations of routines and capabilities: Individuals, processes, and structure”, Journal of Management Studies, Vol. 49 No. 8, pp. $1351-1374$.

Felin, T., Foss, N. J., and Ployhart, R. E. (2015), “The microfoundations movement in strategy and organization theory", The Academy of Management Annals, Vol. 9 No. 1, pp. 575-632.

Finkelstein, S., and Hambrick, D. C. (1996), Strategic leadership: Top executives and their effects on organizations. West Publishing Company, Minneapolis/St. Paul, MN.

Fitzsimmons, S. R. (2013), "Multicultural employees: A framework for understanding how they contribute to organizations", Academy of Management Review, Vol. 38 No. 4, pp. 525-549. 
Fitzsimmons, S. R., Miska, C., and Stahl, G. K. (2011), “Multicultural employees: Global business' untapped resource", Organizational Dynamics, Vol. 40 No. 3, pp. 199-206.

Foss, N.J., and Pedersen, T. (2014), "Microfoundations in strategy research", Strategic Management Journal. DOI: 10.1002/smj.2362.

Foss, N.J., and Pedersen, T. (2019), "Microfoundations in international management research: The case of knowledge sharing in multinational corporations”, Journal of International Business Studies, Vol. 50 No. 9 , pp.1594-1621.

Friedman, R., and Liu, W. (2009), "Biculturalism in management: Leveraging the benefits of intrapersonal diversity", Understanding culture: Theory, research, and application, pp. 343-360.

Furusawa, M., and Brewster, C. (2015), “The bi-cultural option for global talent management: The Japanese/Brazilian Nikkeijin example", Journal of World Business, Vol. 50 No. 1, pp. 133-143.

Gatignon, H., and Kimberly, J. R. (2004), “Globalization and its challenges”, H. G. a. J. R. Kimberly (Ed.), The INSEAD-Wharton Alliance on Globalizing: Strategies for Building Successful Global Businesses, Cambridge University Press, pp. 1-10.

Gavetti, G. (2012), “Toward a behavioral theory of strategy”, Organization Science, Vol. 23 No. 1, pp. $267-285$.

Ghemawat, P. (2005), "Regional strategies for global leadership", Harvard Business Review, Vol. 83 No. 12, pp. 98-108.

Hällgren, M., Rouleau, L., and De Rond, M. (2018), “A matter of life or death: How extreme context research matters for management and organization studies", Academy of Management Annals, Vol. 12 No. 1, pp. 111-153.

Hambrick, D. C., and Fukutomi, G. D. (1991), “The seasons of a CEO's tenure”, Academy of Management Review, Vol. 16 No. 4, pp. 719-742.

Harzing, A.-W. (2000), „An empirical analysis and estension of the Bartlett and Ghoshal typology of multinational companies”, Journal of International Business Studies, Vol. 31 No. 1, pp. 101-120. 
Harzing, A., and Feely, A. (2008), "The language barrier and its implications for HQ-subsidiary relationships", Cross Cultural Management: An International Journal, Vol. 15 No. 1, pp. 49-61.

Harzing, A.-W., Köster, K., and Magner, U. (2011), "Babel in business: The language barrier and its solutions in the HQ-subsidiary relationship", Journal of World Business, Vol. 46 No. 3, pp. 279287.

Heckman, J. J. (1979), "Sample selection bias as a specification error", Econometrica: Journal of the Econometric Society, Vol. 47 No.1, pp. 153-161.

Helfat, C. E, and Peteraf, M. A. (2015), "Managerial cognitive capabilities and the microfoundations of dynamic capabilities", Strategic Management Journal, Vol. 36 No. 6, pp. 831-850.

Hong, H. J. (2010), 'Bicultural competence and its impact on team effectiveness', International Journal of Cross Cultural Management, Vol. 10 No. 1, pp. 93-120.

Hutzschenreuter, T., and Horstkotte, J. (2013), "Performance effects of international expansion processes: The moderating role of top management team experiences", International Business Review, Vol. 22, No. 1, pp. 259-277.

Kiesel, K., and Haghirian, P. (2012), "Bicultural managers and their role in multinational corporations: An exploratory study in Japan”, Cultural Variations and Business Performance: Contemporary Globalism: Contemporary Globalism, pp. 43-55.

Krause, M., and Szymanski, S. (2019), "Convergence versus the middle-income trap: the case of global soccer", Applied Economics, Vol. 51 No. 27, pp. 2980-2999.

Kulkarni, M. (2015), “Language-based diversity and faultlines in organizations”, Journal of Organizational Behavior, Vol. 36 No. 1, pp. 128-146.

Kurtmollaiev, S. (2020), "Dynamic capabilities and where to find them”, Journal of Management Inquiry, Vol. 29 No. (1), pp.3-16.

Leung, K.Y., Maddux, W.W., Galinsky, A.D., and Chiu, C.Y.(2008), "Multicultural experience enhances creativity: The when and how", American Psychologist, Vol. 63 No. 3, pp. 169-181. 
Lucifora, C., and Simmons, R. (2003), "Superstar effects in sport evidence from Italian soccer”, Journal of Sports Economics, Vol. 4 No. 1, pp. 35-55.

Lücke, G., Kostova, T., and Roth, K. (2014), "Multiculturalism from a cognitive perspective: Patterns and implications", Journal of International Business Studies, Vol. 45 No. 2, pp. 169-190.

Maderer, D., Holtbrügge, D., and Schuster, T. (2014), "Professional football squads as multicultural teams: Cultural diversity, intercultural experience, and team performance”, International Journal of Cross Cultural Management, Vol. 14, No. 2, pp.215-238.

Makhija, M. V., Kim, K., and Williamson, S. D. (1997), "Measuring globalization of industries using a national industry approach: Empirical evidence across five countries and over time", Journal of International Business Studies, Vol. 28 No. 4, pp. 679-710.

Marturano, A., Wood, M., and Gosling, J. (2010), Leadership And Language Games (Vol. 9).

Mathieu, J., Maynard, M. T., Rapp, T., and Gilson, L. (2008), “Team effectiveness 1997-2007: A review of recent advancements and a glimpse into the future", Journal of Management, Vol. 34 No. 3, pp.410-476.

Matveev, A. V., and Nelson, P. E. (2004), “Cross cultural communication competence and multicultural team performance: Perceptions of American and Russian managers", International Journal of Cross Cultural Management, Vol. 4 No. 2, pp. 253-270.

McGrath, J. E. (1964), Social psychology: A brief introduction. New York: Holt, Rinehart \& Winston. Mendenhall, M. E., and Bird, A. (2013), "In search of global leadership", Organizational Dynamics, Vol. 42 No. 3, pp. 167-174.

Mendenhall, M. E., Reiche, B. S., Bird, A., and Osland, J. S. (2012), "Defining the "global" in global leadership", Journal of World Business, Vol. 47 No. 4, pp. 493-503.

Mol, M. J., Stadler, C., and Ariño, A. (2017), “Africa: The new frontier for global strategy scholars", Global Strategy Journal, Vol. 7 No. 1, pp. 3-9. 
Mostafiz, M.I., Sambasivan, M., and Goh, S.K. (2019), "Impacts of dynamic managerial capability and international opportunity identification on firm performance", Multinational Business Review, Vol. 27 No. 4, pp. 339-363.

Peeters, T. L., Mills, B. M., Pennings, E., and Sung, H. (2019), "Manager migration, learning-by-hiring, and cultural distance in international soccer", Global Strategy Journal.

Piekkari, R., Vaara, E., Tienari, J. and Säntti, R. (2005), “Integration or disintegration? Human resource implications of a common corporate language decision in a cross-border merger", The International Journal of Human Resource Management, Vol. 16, pp. 330-44.

Pondy, L. R., McCall, M. W., and Lombardo, M. M. (1989), 'Leadership is a language game', Readings in Managerial Psychology, pp. 224-233.

Quinn, R. W., and Worline, M. C. (2008), „Enabling courageous collective action: Conversations from United Airlines flight 93”, Organization Science, Vol. 19 No. 4, pp. 497-516.

Ramsey, J.R., Abi Aad, A., Jiang, C., Barakat, L., and Drummond, V. (2016), “Emergence of cultural intelligence and global mindset capital: a multilevel model", Multinational Business Review, Vol. 24 No. 2, pp. 106-122.

Reiche, B. S., Bird, A., Mendenhall, M. E., and Osland, J. (2017), “Contextualizing leadership: A typology of global leadership roles", Journal of International Business Studies, Vol. 48, pp. 552572.

Roth, K., and Kostova, T. (2003), "The use of the multinational corporation as a research context", Journal of Management, Vol. 29, pp.883-902.

Selmier II, W. T., Newenham-Kahindi, A., and Oh, C. H. (2015), "Understanding the words of relationships": Language as an essential tool to manage CSR in communities of place", Journal of International Business Studies, Vol. 46, No. 2, pp.153-179.

Selmier II, W. T., and Oh, C. H. (2012), "International business complexity and the internationalization of languages", Business Horizons, Vol. 55, No. 2, pp.189-200. 
Selmier, W. T., and Oh, C. H. (2013), "The power of major trade languages in trade and foreign direct investment", Review of International Political Economy, Vol. 20, No. 3, pp.486-514.

Smart, D. L., and Wolfe, R. A. (2003), "The contribution of leadership and human resources to organizational success: An empirical assessment of performance in Major League Baseball”, European Sport Management Quarterly, Vol. 3 No. 3, pp. 165-188.

Steyaert, C., Ostendorp, A., and Gaibrois, C. (2011), “Multilingual organizations as 'linguascapes': Negotiating the position of English through discursive practices", Journal of World Business, Vol. 46 No. 3, pp. 270-278.

Szymanski, M., Fitzsimmons, S. R., and Danis, W. M. (2019), "Multicultural managers and competitive advantage: Evidence from elite football team”, International Business Review, Vol. 28 No. 2, pp. $305-315$.

Szymanski, M., Wolfe, R.A., Danis, W., Lee, F. and Uy, M.A. (2020), “Sport and international management: Exploring research synergy", Thunderbird International Business Review. https://doi.org/10.1002/tie.22139

Tadmor, C. T., Tetlock, P. E., and Peng, K. (2009), “Acculturation strategies and integrative complexity the cognitive implications of biculturalism", Journal of Cross-Cultural Psychology, Vol. 40 No. 1, pp. 105-139.

Teece, D. J. (2007), “Explicating dynamic capabilities: The nature and microfoundations of (sustainable) enterprise performance", Strategic Management Journal, Vol. 28 No. 13, pp. 1319- 1350.

Teece, D. J. (2014), “The foundations of enterprise performance: Dynamic and ordinary capabilities in an (economic) theory of firms", Academy of Management Perspectives, Vol. 28 No. 4, pp.328-352.

Teece, D.J., Pisano, G., and Shuen, A. (1997), “Dynamic Capabilities and Strategic Management”, Strategic Management Journal, Vol. 18 No. 7, pp. 509-533.

Tenzer, H., and Pudelko, M. (2015), “Leading across language barriers: Managing language-induced emotions in multinational teams", The Leadership Quarterly, Vol. 26 No. 4, pp. 606-625. 
Tenzer, H., and Pudelko, M. (2017), “The influence of language differences on power dynamics in multinational teams", Journal of World Business, Vol. 52 No. 1, pp. 45-61.

van Bakel, M., and Salzbrenner, S. (2019), "Going abroad to play: Motivations, challenges, and support of sports expatriates", Thunderbird International Business Review, Vol. 61 No. 3, pp. 505-517.

Vora, D. and Kostova, T. (2019), "Antecedents of psychological attachment in multinational enterprises", Multinational Business Review.

Vora, D., Martin, L., Fitzsimmons, S. R., Pekerti, A. A., Lakshman, C., and Raheem, S. (2019), "Multiculturalism within individuals: A review, critique, and agenda for future research", Journal of International Business Studies, Vol. 50 No. 4, pp. 499-524.

Weick, K. E. (1993), “The collapse of sensemaking in organizations: The Mann Gulch disaster", Administrative Science Quarterly, Vol. 38. No. 4, pp. 628-652.

Welch, D. E., and Welch, L. S. (2008), “The importance of language in international knowledge transfer", Management International Review, Vol. 48 No. 3, pp. 339-360.

Welch, D. E., Welch, L. S., and Marschan-Piekkari, R. (2001), “The persistent impact of language on global operations", Prometheus, Vol. 19 No. 3, pp. 193-209.

Wolfe, R. A., Weick, K. E., Usher, J. M., Terborg, J. R., Poppo, L., Murrell, A. J., ... and Jourdan, J. S. (2005), "Sport and organizational studies exploring synergy", Journal of Management Inquiry, Vol. 14 No. 2, pp. 182-210.

Zander, L. (2005), “Communication and country clusters: A study of language and leadership preferences”, International Studies of Management and Organization, Vol. 35 No. 1, pp. 83-103.

Zander, L., Mockaitis, A. I., and Harzing, A.-W. (2011), "Standardization and contextualization: A study of language and leadership across 17 countries", Journal of World Business, Vol. 46 No. 3, pp. 296-304. 


\section{TABLES}

Table 1. Descriptive statistics and correlations in Sample 1.

\begin{tabular}{|c|c|c|c|c|c|c|c|c|c|c|c|c|}
\hline$N=291$ & Mean & Std. Dev. & Min & Max & 1 & 2 & 3 & 4 & 5 & 6 & 7 & 8 \\
\hline 1. Wins Per Game (WPG) & 0.365 & 0.154 & 0 & 0.852 & & & & & & & & \\
\hline 2. Team Average Age & 22.570 & 1.535 & 20 & 27 & $-0.157 * * *$ & & & & & & & \\
\hline 3. Team Average Salary ${ }^{\alpha}$ & 29.565 & 49.764 & 1 & 400 & $0.385 * * *$ & $0.110^{*}$ & & & & & & \\
\hline $\begin{array}{l}\text { 4. Number of Nationalities on } \\
\text { the Team }\end{array}$ & 9.302 & 5.282 & 1 & 30 & $0.129 * *$ & $-0.143 * *$ & $0.487 * * *$ & & & & & \\
\hline 5. Manager's Age & 48.103 & 7.419 & 29 & 70 & $0.110^{*}$ & $-0.178 * * *$ & 0.068 & 0.025 & & & & \\
\hline 6. Manager's Tenure & 1.257 & 2.435 & 0 & 26 & $0.195 * * *$ & -0.056 & $0.198 * * *$ & $0.193 * * *$ & $0.286 * * *$ & & & \\
\hline 7. Foreign Manager (dummy) & 0.189 & & & & $0.179 * * *$ & -0.025 & $0.256^{* * *}$ & $0.205^{* * *}$ & 0.063 & $0.111 *$ & & \\
\hline 8. Number of languages spoken & 1.955 & 1.254 & 1 & 9 & $0.273 * * *$ & $-0.119 * *$ & 0.022 & 0.004 & $0.117 * *$ & 0.006 & $0.326^{* * *}$ & \\
\hline $\begin{array}{l}\text { 9. Multicultural Coach } \\
\text { (dummy) }\end{array}$ & 0.137 & & & & $0.071^{*}$ & -0.051 & 0.033 & 0.036 & -0.011 & $0.122^{* *}$ & $0.190 * * *$ & $0.301 * * *$ \\
\hline
\end{tabular}

$* p<0.1 ; * * p<0.05 ; * * * p<0.01$.

${ }^{\alpha}$ Descriptive statistics for team average salary per week; correlations provided for the logarithmically transformed variable 
Table 2. Descriptive Statistics and Correlations in Sample 2.

\begin{tabular}{|c|c|c|c|c|c|c|c|c|c|c|c|c|}
\hline$N=191$ & Mean & Std. Dev. & Min & Max & 1 & 2 & 3 & 4 & 5 & 6 & 7 & 8 \\
\hline 1. Wins Per Game (WPG) & 0.395 & 0.231 & 0 & 1 & & & & & & & & \\
\hline 2. Team Average Age & 24.021 & 2.59 & 19 & 31 & 0.018 & & & & & & & \\
\hline 3. Team Average Salary ${ }^{\alpha}$ & 26.681 & 58.350 & 1 & 400 & $0.138^{*}$ & $-0.170 * *$ & & & & & & \\
\hline $\begin{array}{l}\text { 4. Number of Nationalities on } \\
\text { the Team }\end{array}$ & 6.937 & 5.204 & 1 & 23 & 0.023 & $-0.414 * * *$ & $0.572 * * *$ & & & & & \\
\hline 5. Manager's Age & 49.167 & 8.131 & 33 & 70 & 0.002 & -0.044 & 0.001 & -0.054 & & & & \\
\hline 6. Manager's Tenure & 1.738 & 2.621 & 0 & 26 & 0.022 & -0.081 & $0.132 *$ & $0.198 * * *$ & $0.239 * * *$ & & & \\
\hline 7. Foreign Manager (dummy) & 0.30 & & & & 0.062 & $0.217 * * *$ & 0.079 & 0.070 & 0.103 & 0.004 & & \\
\hline 8. Number of languages spoken & 2.126 & 1.355 & 1 & 8 & -0.004 & -0.110 & 0.090 & $0.188 * * *$ & $0.142 *$ & $0.116^{*}$ & $0.391 * * *$ & \\
\hline $\begin{array}{l}\text { 9. Multicultural Coach } \\
\text { (dummy) }\end{array}$ & 0.194 & & & & $0.121^{*}$ & $-0.214 * * *$ & -0.006 & 0.080 & 0.027 & $0.272 * * *$ & $0.170^{* *}$ & $0.278 * * *$ \\
\hline
\end{tabular}

$$
* p<0.1 ; * * p<0.05 ; * * * p<0.01
$$

${ }^{\alpha}$ Descriptive statistics for team average salary per week; correlations provided for the logarithmically transformed variable

Table 3. Ordinary Least Squares Regression results

\begin{tabular}{|c|c|c|c|c|c|}
\hline \multirow[t]{2}{*}{$N=291$} & \multicolumn{4}{|c|}{ DV: Team Performance (WPG) } & \multirow[b]{2}{*}{$\begin{array}{c}\text { Full } \\
\text { Model }\end{array}$} \\
\hline & $\begin{array}{c}\text { Base } \\
\text { Model } \\
\end{array}$ & Model 1 & Model 2 & Model 3 & \\
\hline Team Average Age & $-0.028 * * *$ & $-0.027 * * *$ & $-0.026^{* * *}$ & $-0.028 * * *$ & $-0.027 * * *$ \\
\hline Team Average Salary & $0.163 * * *$ & $0.156^{* * *}$ & $0.151 * * *$ & $0.156^{* * *}$ & $0.151 * * *$ \\
\hline Number of Nationalities on the Team & -0.001 & -0.001 & -0.001 & -0.001 & -0.001 \\
\hline Manager's Age & & -0.001 & -0.001 & -0.001 & -0.001 \\
\hline Manager's Tenure & & $0.008 * *$ & $0.008 * *$ & $0.008 * *$ & $0.008 * *$ \\
\hline Foreign Manager (dummy) & & $0.044 * *$ & $0.027^{*}$ & $0.044 * *$ & $0.027^{*}$ \\
\hline Number of languages spoken & & & $0.018 * *$ & & $0.020 * *$ \\
\hline Multicultural Coach (dummy) & & & & -0.005 & -0.028 \\
\hline Fixed-effects for leagues & Yes & Yes & Yes & Yes & Yes \\
\hline $\operatorname{Adj} . R^{2}$ & 0.450 & 0.466 & 0.479 & 0.465 & 0.481 \\
\hline$R^{2}$ difference & & $0.016 * * *$ & $0.029 * * *$ & $0.015 * * *$ & $0.031 * * *$ \\
\hline
\end{tabular}


Table 4. Ordinary Least Squares Regression results

\begin{tabular}{|c|c|c|c|c|c|}
\hline \multirow[t]{2}{*}{$N=191$} & \multicolumn{4}{|c|}{ DV: Team Performance (WPG) } & \multirow[b]{2}{*}{$\begin{array}{c}\text { Full } \\
\text { Model }\end{array}$} \\
\hline & $\begin{array}{c}\text { Base } \\
\text { Model }\end{array}$ & Model 1 & Model 2 & Model 3 & \\
\hline Team Average Age & $0.015^{*}$ & 0.012 & $0.012 * * *$ & $0.012 * * *$ & $0.012 * * *$ \\
\hline Team Average Salary & $0.044 * *$ & $0.044 * *$ & $0.045 * *$ & $0.045 * *$ & $0.044 * *$ \\
\hline Number of Nationalities on the Team & -0.003 & -0.002 & $-0.002 * *$ & 0.002 & 0.003 \\
\hline Manager's Age & & 0.001 & -0.002 & -0.001 & 0.002 \\
\hline Manager's Tenure & & -0.001 & -0.001 & -0.004 & -0.004 \\
\hline Foreign Manager (dummy) & & 0.004 & 0.001 & -0.009 & -0.006 \\
\hline Number of languages spoken & & & -0.001 & & -0.004 \\
\hline Multicultural Coach (dummy) & & & & $0.091 * *$ & $0.093 * *$ \\
\hline $\operatorname{Adj.} R^{2}$ & 0.693 & 0.711 & 0.727 & 0.748 & 0.757 \\
\hline$R^{2}$ difference & & $0.018 * * *$ & $0.016 * * *$ & $0.037 * * *$ & $0.046^{* * *}$ \\
\hline
\end{tabular}

